Revista Oficial del Poder Judicial

ÓRGANO DE INVESTIGACIÓN DE LA CORTE SUPREMA DE JUSTICIA DE LA REPÚBLICA DEL PERÚ

Vol. 10, n. ${ }^{\circ}$ 12, julio-diciembre, 2019, 27-56

ISSN versión impresa: 1997-6682

ISSN versión electrónica: 2663-9130

DOI: https://doi.org/10.35292/ropj.u10i12.23

\title{
La medida cautelar de anotación de demanda y una reciente decisión del Tribunal Constitucional
}

\author{
Precautionary measure of \\ Lis Pendens and a recent decision \\ of the Constitutional Court \\ 0 (2) \\ MARTíN ALEJANDRO HURTADO REYES \\ Corte Suprema de Justicia de la República del Perú \\ (Lima, Perú) \\ Contacto: mhurtador@pj.gob.pe \\ https://orcid.org/0000-0003-0731-7644
}

\begin{abstract}
RESUMEN
En el artículo se analiza la sentencia del Tribunal Constitucional recaída en el Expediente n. ${ }^{\circ}$ 06920-2013-PA/TC Lima, donde en decisión por mayoría se desestima el recurso de amparo interpuesto contra la resolución judicial que discutió la posibilidad de ordenar que se levante la medida cautelar de anotación de demanda dictada en un proceso laboral, sobre un bien que posteriormente fuese otorgado en propiedad a un tercero adjudicatario. En tal sentido,
\end{abstract}


precisa la falta de idoneidad de la medida cautelar de anotación de demanda para garantizar decisiones que se vinculen con acreencias laborales, así como su inutilidad para definir la prelación en el pago de créditos. Asimismo, cuestiona que no se haya respetado el presupuesto de adecuación de la citada medida respecto a lo que se pretende proteger; $y$ el hecho de que al no haberse ordenado el levantamiento de la medida cautelar de anotación de demanda, se ha afectado gravemente el derecho de propiedad de la parte que obtuvo la adjudicación del bien por remate.

Palabras clave: anotación de demanda, criterio de adecuación, derechos laborales, prelación, adjudicación, levantamiento de medida cautelar, derecho de propiedad, amparo.

\section{ABSTRACT}

This article analyzes the judgment of the Constitutional Court in the matter of Docket No. 06920-2013-PA/TC Lima, in which, by a majority decision, the Court dismissed the appeal for amparo filed against the judgment that discussed the possibility of lifting the preventive measure of lis pendens dictated in a labor proceeding, on a property that was subsequently granted in ownership to a third person. In this regard, the article examines the unsuitable nature of the precautionary measure of lis pendens to guarantee decisions related to labor debts, as well as their lack of utility to prioritize the payment of credits. Furthermore, it questions the fact that the adjustment of the referred measure with respect to the protected interest was not respected; and that the precautionary measure of lis pendens was not lifted thereby seriously affecting the property rights of the party who obtained the property in an auction. 
Key words: lis pendens, criteria of adjustment, labor rights, priority, award, lifting of the precautionary measure, property rights, amparo.

Recibido: 26/08/19 Aceptado: 30/09/19

\section{INTRODUCCIÓN}

Se nos pide realizar comentarios respecto de la sentencia del Tribunal Constitucional en relación con la posición asumida en la sentencia contenida en el Expediente n. ${ }^{\circ}$ 06920-2013-PA/TC Lima. En dicha sentencia se discutió, en un proceso de amparo contra resolución judicial, la posibilidad de ordenar que se levante la medida cautelar de anotación de demanda dictada en un proceso laboral.

Se trata de una demanda de amparo contra resolución judicial postulada por la empresa Corporación Peruana de Productos Químicos S. A. contra la resolución de la Primera Sala Civil de la Corte de Lima, por la que se declaró infundada la demanda. La empresa alega que el inmueble afectado por esta medida cautelar lo adquirió a través de un remate público; sin embargo, no se lograron levantar las medidas de anotación de demanda que afectan el bien, debido a diversos procesos que iniciaron trabajadores contra la Cooperativa Industrial Cristal Murano.

Se tiene como antecedente que el pedido de levantamiento de medida cautelar de anotación de demanda fue aceptado en primer grado, empero, en segundo grado la decisión fue desestimada (revocada) al considerar que resultaba impredecible que el embargo en forma de retención pueda cubrir el adeudo del trabajador, tras existir diversas incidencias sobre la preferencia del pago tramitada por la propia Sala Laboral emplazada. Asimismo, la demanda de amparo fue estimada por el juez de primer grado tras considerar que, producido el remate judicial, el bien adquirido no puede ser utilizado para pagar las deudas laborales por las cuales se anotaron 
las diversas demandas laborales, de modo que ello impide el ejercicio de uno de los atributos del derecho de propiedad. En segundo grado, la Sala Superior revocó la apelada considerando que la recurrente adquirió el bien conociendo sus antecedentes registrales y que de conformidad con lo que dispone el artículo 739 del CPC se debe levantar todo gravamen que pesa sobre el bien, pero no la medida cautelar de anotación de demanda.

En su momento, el Tribunal Constitucional, con cuatro votos, decidió desestimar el RAC y por ello declarar infundada la demanda indicando como argumentos los siguientes:

a) De levantarse la medida cautelar de anotación de demanda desaparece la posibilidad de que alguno de los acreedores pueda reclamar la prioridad en la satisfacción de sus créditos.

b) Se trata de una medida necesaria, la cual si bien obstaculiza el poder de disposición del bien, tiene también por finalidad satisfacer ciertas exigencias relacionadas con el principio de seguridad jurídica (satisfacción de derecho laboral).

c) Es una carga no excesiva que será llevada temporalmente por las personas que adquieren un bien mediante remate judicial.

El voto en minoría y en especial el voto de la profesora Ledesma Narváez presenta una visión diferente del tema:

a) Acude a la finalidad de las medidas cautelares y concretamente a la finalidad de la anotación de demanda.

b) Utilidad de la anotación de demanda en las pretensiones dinerarias.

c) Prelación de las acreencias laborales.

d) Principio de persecutoriedad. 


\section{PLANTEAMIENTO DEL PROBLEMA}

Existen varios tópicos que se pueden ver involucrados en la situación planteada por el caso que llegó al Tribunal Constitucional, por lo que consideramos necesario plantear algunas interrogantes:

- ¿Se debe levantar la medida cautelar de anotación de demanda cuando se produce la adjudicación del bien por remate derivado de un proceso en el que se discute una acreencia laboral?

- ¿El no levantamiento de la medida cautelar de anotación de demanda, en estos casos, afecta el derecho de propiedad del adjudicatario?

\section{APUNTES PREVIOS}

\subsection{La medida cautelar de anotación de demanda}

\subsubsection{Concepto}

Conocida en doctrina como anotación de litis, para De Lazzari es la cautela que permite alertar sobre la existencia de un juicio, evitando que terceros que contratan sobre bienes registrables en él implicados puedan invocar buena fe frente a quien la obtuvo. Como se advierte, cumple una función esencial de publicidad, sin restringir las facultades de disposición del dueño de la cosa a la cual se refiere la medida (1998: 531).

La anotación de demanda es una medida cautelar distinta al embargo o secuestro, su objeto principal es la publicidad, es decir, poner en conocimiento de una generalidad de personas la existencia de un proceso judicial en trámite por el cual se está cuestionando la realidad jurídica de un bien o derecho registrado. El tercero que se vincule con el bien o derecho, desde que toma contacto con este, tiene la expectativa incierta de que luego de culminado el proceso con sentencia firme, la realidad jurídica registral del bien o derecho inscrito puede sufrir una alteración que lo afecte. La importancia 
de la anotación de demanda en el registro correspondiente estriba, según Alsina, en que el tercero adquiriente o aquel a cuyo favor se constituye un derecho real, no pueden alegar ignorancia, debiendo soportar, en consecuencia, los efectos de la sentencia (1941-1943: 327, t. III).

Para Monroy Gálvez esta medida cautelar se concede en aquellos procesos en los que sus consecuencias afecten a un bien inscrito (1987: 56).

No interesa si con la demanda se está ejerciendo una pretensión de carácter real o personal, lo significativo es el efecto que producirá la sentencia en el Registro, de ser amparada. Aunque debe tomarse en cuenta que la anotación de demanda debe ser la adecuada a la pretensión postulada, es decir, que tenga concordancia o relación directa con lo que se procura con la pretensión.

La medida cautelar de anotación de demanda se constituye como pilar fundamental en los procesos de cognición, en los cuales la sentencia modificará o generará un determinado efecto jurídico en el Registro, con respecto a los bienes o derechos que se discuten en el proceso judicial.

La anotación de demanda sirve para publicitar una litis a través del Registro, evita que terceros que se vinculen con bienes o derechos registrados puedan alegar buena fe en el futuro, basados en el Registro. Es la mejor forma de garantizar el resultado de un proceso, pues con ella se hace saber a todos los que se vinculen con bienes o derechos registrados, que sobre estos existe un proceso judicial, que se encuentran en litis, que están cuestionados judicialmente; por lo cual, si se vincula con ellos, sufrirá las consecuencias que se deriven (favorables o desfavorables) del resultado del proceso judicial (sentencia firme).

Al igual que el embargo en la modalidad de inscripción, la anotación de demanda tiene gran acercamiento al derecho registral, 
pues por su naturaleza en sede registral y además por disposición legal expresa, esta medida cautelar se constituye en una anotación preventiva.

\section{ASPECTOS PROCESALES PARA LA CONCESIÓN DE LA ANOTACIÓN DE DEMANDA}

En principio debemos tomar en cuenta que la anotación de demanda es una medida cautelar, por lo tanto, debería estar sujeta a los requisitos y exigencias de toda medida cautelar, es decir, debe definirse la verosimilitud, peligro en la demora, adecuación y contracautela. Sin embargo, dada su naturaleza esencialmente de publicidad de un proceso judicial en el Registro, tiene sus propios requisitos que la diferencian de las demás.

\subsection{Necesidad de una demanda admitida}

Significa que la anotación de demanda presupone siempre la iniciación de un proceso, esto es, la existencia de una demanda admitida previa a su concesión, por lo cual no se concibe la anotación de litis sin que exista un proceso en trámite. No sería congruente, en consecuencia, solicitar una medida cautelar de anotación de demanda fuera del proceso. Sería un contrasentido, ya que se anota o se inscribe en el Registro una demanda admitida (esto es, cuando el proceso se encuentra en trámite), no es posible admitir una demanda que aún no se ha postulado ${ }^{1}$.

1 Aunque actualmente se suele utilizar para estos fines la llamada anotación de pretensión futura, que cuadra más con una medida cautelar genérica, que se da en circunstancias en las cuales la anotación de demanda no es admisible, pero, por la urgencia, se necesita anotar la existencia de un proceso futuro. Es una forma de publicitar un proceso que no existe, pero que debería existir en el futuro. 
Esto significa que el pedido de anotación de demanda en el Registro depende de la admisión de la demanda postulada. Si no hay demanda admitida, no es posible atender un pedido de esta naturaleza.

\subsection{Verosimilitud del derecho}

Como en cualquier otra medida cautelar, resulta necesario que el juez termine convencido de la apariencia del derecho que invoca el actor al postular el pedido de anotación de demanda. Sin embargo, no hay una regla específica en cuanto a la anotación de demanda para sustentar la verosimilitud del derecho que se invoca, por lo que me animo a decir que si la verosimilitud del derecho invocado significa tener determinado grado o porcentaje de probabilidad para que el juez estime la pretensión en la sentencia, entonces, el actor debe brindar un grado aceptable de probabilidad al juez para pasar este presupuesto.

Para algún sector de la doctrina, el único recaudo que se debería establecer para la concesión de esta medida cautelar es la existencia de la verosimilitud del derecho. En tal sentido, Alsina sostiene que basta la simple verosimilitud del derecho, que será apreciada discrecionalmente por el juez en cada caso, teniendo en cuenta los fundamentos de la demanda y las circunstancias de hecho que la rodean (1941-1943: 330).

La situación más importante en estos casos, según mi opinión, está en el peligro en la demora, pues me parece que se debe postular la necesidad de anotar la demanda para evitar que el Registro cambie o se modifique por el accionar del demandado o de terceros, de tal manera que se eviten serios perjuicios en el actor, en el futuro, o que se genere una ineficacia de lo decidido. Aunque esta situación encaja más con el peligro en la demora. 


\subsection{Peligro en la demora}

Si la anotación de demanda busca dar publicidad de la existencia de una litis con el objeto de eliminar la buena fe que pudieran alegar con posterioridad terceros registrales que se vinculen con él, entonces resulta totalmente claro que el peligro de la demora forma parte de la demanda. Este se vincula, además, a la verosimilitud del derecho, puesto que el peligro está ligado a la inmediatez con que se debe llegar al Registro, anotar la litis y evitar una modificación -algunas veces provocada - de la realidad registral del derecho o bien inscrito, con el consecuente fracaso irremediable de lo que se puede resolver en la sentencia.

Al respecto, De Lazzari indica que, en cuanto a la verosimilitud del derecho, si bien debe reunirse en todos los casos, siendo la anotación menos grave en sus efectos el embargo, en tanto permite la disponibilidad del bien, la carga de admisibilidad se atenúa manifiestamente. En cuanto al peligro en la demora, citando una jurisprudencia argentina, indica que esta se encuentra presumida o ínsita en la ley, relativa al ofrecimiento de contracautela, aunque la graduación sea más benigna. Igualmente, pueden seguirse perjuicios al titular del dominio, que verá desvalorizada la cosa por la existencia de la prenotación (1998: 334-336).

En síntesis, en la anotación de demanda el juez debe estar convencido de una simple verosimilitud del derecho. Pero debe tener sumo cuidado de que si no se concede la medida cautelar, pueden generarse graves perjuicios en contra del demandante, pues se pierde la oportunidad de anotar la litis y hacerla pública. De tal forma que, si no se hace, la eficacia del proceso simplemente no servirá, o por lo menos no tendrá utilidad para el demandante.

Esta situación se presenta en los procesos de nulidad de acto jurídico, otorgamiento de escritura pública, prescripción adquisitiva, entre otros, en los cuales muchas veces lo más importante resulta 
proteger la eficacia del proceso, dando lugar a la anotación de demanda porque el Registro puede variar en minutos y el resultado del proceso no le servirá al actor si no se logra hacer pública la litis, teniendo en cuenta siempre un grado aceptable de verosimilitud.

\subsection{Adecuación}

La adecuación debe ser entendida como la correlación y coherencia que debe existir entre lo que se pretende cautelar en el proceso principal y la tutela cautelar que se dicta, esto es, que el pedido de tutela cautelar debe adecuarse a la pretensión que se trata de garantizar.

El que una medida cautelar sea «adecuada» depende del nexo que se establece entre el concreto derecho invocado y el peligro que (igualmente) se invoca, en tanto y en cuanto la tutela cautelar tiene por objeto «neutralizar» ese peligro durante toda la pendencia del proceso de fondo (salvo, obviamente, una mutación ulterior de las circunstancias). Por lo cual el profesor Priori ha señalado que la relación entre medida cautelar y pretensión planteada en la demanda es de idoneidad, y a ello se refiere la adecuación como presupuesto de las medidas cautelares (2006: 87).

Para nuestro Tribunal Constitucional «este presupuesto exige que el juzgador deba adecuar la medida cautelar solicitada a aquello que se pretende asegurar, debiendo dictar la medida que de menor modo afecte los bienes o derechos de la parte demandada o, en todo caso, dictar la medida que resulte proporcional con el fin que se persigue» (STC n. ${ }^{\circ} 0023-2005-\mathrm{PI} / \mathrm{TC}$ ). De lo que se puede inferir que el presupuesto de adecuación tendría los siguientes elementos:

a) El juez al conceder tutela cautelar debe utilizar criterios idóneos que lo ayuden a sintonizar lo que se pide (con la medida cautelar) con lo que se pretende asegurar. De tal manera que 
exista una relación directa entre ambas, lo que implica la presencia de una conexión jurídica entre ellas.

b) Esta adecuación no debe ser lesiva a los bienes o derechos del destinatario de la tutela cautelar o en todo caso debe serlo en la medida de lo necesario.

c) La medida concedida no debe ser excesiva ni arrolladora de los intereses del demandado, debe guardar proporcionalidad con respecto a lo que se pretende proteger.

La adecuación consiste en la congruencia y proporcionalidad que debe existir entre el pedido cautelar y la situación jurídica o fáctica que es objeto de la aseguración. La inobservancia de este requisito distorsiona la finalidad de las medidas, convirtiéndolas, en muchas ocasiones, en mecanismos de presión psicológica o medios para obtener una tutela satisfactiva. En otras palabras, en medidas cautelares ilícitas (Monroy Palacios 2002: 364).

En la anotación de demanda es de suma importancia la adecuación, ya que el juez debe tomar en cuenta dos situaciones. La primera, que la medida solicitada tenga relación directa con lo que se busca con la pretensión principal, es decir, que la anotación de demanda procure darle eficacia a la decisión que se obtenga en la sentencia. La segunda, que esta medida no afecte de forma ostensible la esfera jurídica patrimonial del demandado, que no es desproporcionada, sino más bien que responda a criterios de razonabilidad y proporcionalidad.

Considero que la anotación de demanda es una de aquellas que mejor protección le brinda al demandante en casos en los cuales la pretensión postulada se vincule a situaciones que se verán cristalizadas en el Registro. 


\subsection{Contracautela}

Es significativa la expectativa negativa que genera frente a terceros el hecho de que un bien o derecho registrado se encuentre afectado por una anotación de demanda. Esto implica de alguna forma la disminución de su valor de compra o quizá la desconfianza total de los terceros que quisieran vincularse contractualmente con el titular del derecho inscrito. Es alto el costo que han tenido que pagar aquellos que se vincularon con un bien afectado con esta medida cautelar, pues finalmente luego de concluido el proceso su inversión se fue por la borda.

$\mathrm{Si}$ todas estas consecuencias pueden generar la anotación de demanda, entonces resulta necesario establecer un régimen de contracautela que proteja adecuadamente los intereses del demandado y titular del derecho inscrito, si le asiste la razón en el pronunciamiento final.

El régimen de contracautela en las medidas cautelares de anotación de demanda es variado según las circunstancias del caso, pero en la práctica es usual que se exija únicamente una caución juratoria, aunque nada impide que de acuerdo con el caso en particular se pueda solicitar una garantía real $\mathrm{u}$ otra que proteja adecuadamente los intereses del demandado.

Podetti señala que ningún profesional con alguna experiencia ignora esas demandas por reivindicación de grandes extensiones de tierras, cuyo valor actual asciende a centenas de miles y aún de millones, que se transan por unos pocos pesos, que el demandado paga para evitarse las consecuencias desastrosas de un pleito con un insolvente o los perjuicios dimanados de un embargo o de una anotación de litis, sin más contracautela que la caución juratoria; pero tampoco ignora la situación inversa, de un demandado que usufructuando el inmueble, dilata por años la terminación del litigio (1943: 150). 


\section{SITUACIONES ADICIONALES QUE SE DEBEN TENER EN CUENTA PARA ACCEDER A ESTA MEDIDA CAUTELAR}

\subsection{Se debe tratar de bienes o derechos registrados}

Puede ser que la pretensión que se discute en el proceso principal esté vinculada a una reivindicación, simulación de acto jurídico, prescripción adquisitiva, otorgamiento de escritura pública, nulidad de compraventa, nulidad de testamento, etc.; sin embargo, esto per se no garantiza la procedencia de esta medida cautelar. La anotación de demanda tiene trascendencia cuando la pretensión procesal tiene directa relación con un bien o derecho inscrito. En otras palabras, en el ejemplo de la reivindicación de un inmueble se admitirá la anotación de demanda siempre que este se encuentre registrado. $\mathrm{O}$ si se pretende efectivizar una obligación de escriturar la cautela solo será procedente si el bien inmueble transferido cuenta con registro.

Entonces, digamos que la característica principal de esta medida cautelar estriba en el binomio pretensión y bien o derecho registrado, la ausencia de estos elementos imposibilita la expedición de esta cautela. Según De Lazzari, es necesario que la pretensión de fondo pueda tener como consecuencia la modificación de una inscripción en el registro correspondiente (1998: 534).

Consideramos que la anotación de demanda es procedente si se adecua a lo que se busca con la pretensión postulada con la demanda. Pero se requiere que el bien o el derecho que es materia de discusión se encuentre registrado, que tenga referencia en el registro.

\subsection{Ejecución}

Siendo la anotación de demanda una medida cautelar que en sede registral es considerada un anotación preventiva ${ }^{2}$, esta se debe

2 Para Balarezo Forttini, dependiendo del tipo de anotación preventiva de que se trate, serán preinscripciones que publican la existencia de un derecho en vías 
ejecutar por el registrador público con el acceso o anotación al registro correspondiente.

Corresponde al registro realizar la calificación de la rogatoria judicial para definir la procedencia de la inscripción de la medida cautelar, cuidando sobre todo que exista concordancia entre el titular registral y quien aparece como demandado. La idea es que se ejecute la medida cautelar sobre un bien que sea de titularidad del demandado, a fin de evitar perjuicio contra terceros que no son parte en el proceso.

Es a través del registro que se hace pública la afectación del bien con esta medida cautelar, por ello decíamos que la medida cautelar de anotación de demanda sirve para publicitar a través del registro la existencia de un proceso judicial en el que se decidirá con la sentencia firme la variación del registro.

La publicidad registral permite que todos sin excepción sepan que existe en el Poder Judicial un proceso en el que se discute una pretensión que puede variar el Registro. Es la mejor forma de hacer público un litigio.

\subsection{Compatibilidad con el derecho inscrito}

Debemos ratificar nuestra opinión respecto de la compatibilidad que debe existir con el mandato judicial (medida cautelar de anotación de demanda) y los antecedentes registrales del bien o derecho que se pretenden afectar. Esto quiere decir que el demandado debe aparecer

de inscripción, pero todavía no inscrito (es el caso de los asientos extendidos por defectos subsanables o por no estar inscrito el derecho de donde emane la transmisión o el gravamen); o asientos de contradicción, pues publican una eventual y futura rectificación de registro (como en el caso de la anotación de demanda) o asientos que dotan de determinados créditos de garantía o de preferencia frente a otros (por ejemplo, en la anotación de embargo) (1997: A-107). 
con derecho inscrito en el Registro para que se pueda acceder a la inscripción.

La calificación de títulos de origen judicial por parte del registrador debe hacerse respetando los principios registrales que se encuentran involucrados en la calificación, de tal forma que si el titular registral ya no es el demandado, no se deberá acceder al pedido judicial, salvo que el juez insista en la inscripción luego de que el registrador le haga la observación.

En estos casos se debe aplicar el principio de prioridad excluyente, regulado en el artículo 2017 del Código Civil, según el cual «no podría inscribirse ningún título incompatible con otro ya inscrito, aunque este sea de fecha anterior», que tiene concordancia con el artículo 673 del Código Procesal Civil, que señala que «el registrador cumplirá la orden por su propio texto, siempre que la medida resulte compatible con el derecho ya inscrito».

Esta calificación registral tendrá en cuenta igualmente el principio de legitimación establecido en el artículo 2013 del Código Civil, pues las situaciones y titularidades que el Registro publicita se encuentran dotadas de presunción de exactitud, toda vez que el contenido de las inscripciones se presume cierto hasta que se modifique.

De este modo, se tiene que la actividad registral y los principios que la regulan juegan un papel importante en lograr la eficacia de la decisión judicial.

\subsection{La medida no impide la enajenación del bien}

Como sabemos, la anotación de una medida cautelar en el Registro de un determinado bien o derecho no lo sustrae de la esfera del comercio, es decir, que como cualquier otro bien puede ser transferido, gravado, etc. No se convierte en un bien fuera del comercio, aunque como veremos más adelante la sola inscripción 
de una medida de esta naturaleza puede generar una serie de problemas en el titular del derecho, sobre todo respecto del ejercicio del derecho de propiedad.

En este caso la anotación de demanda tiene por finalidad desvirtuar oportunamente la buena fe que pueda alegar el tercero registral ${ }^{3}$ que se vinculó con el bien, pues tuvo oportuno conocimiento (advertencia) de la existencia de un litigio y de que el resultado de este podía variar la situación registral del bien.

Al respecto, Balarezo concluye que la anotación de demanda tampoco implica la prohibición de disponer del bien, sino que advierte a posibles contratantes de la existencia de un proceso en el que se discuten los derechos inscritos evitando con ello la aparición del tercero registral. En tal virtud, en caso la sentencia dictada en el principal sea favorable al demandante, el tercero no podrá ser mantenido en su adquisición, por no reunir los requisitos contemplados en el artículo 2014 del Código Civil. Agrega además que los contratos de disposición respecto del bien sobre el cual recae la anotación de embargo o la anotación de demanda, según corresponda, no son nulos, ni siquiera anulables, sino que son perfectamente válidos entre las partes, aunque de naturaleza aleatoria, regulados, por ello, por el artículo 1536 del Código Civil (Balarezo 1997: A-110).

3 El concepto de tercero registral se encuentra vinculado con el principio de fe pública registral, ya que la protección que esta origina alcanza a aquel directamente. El artículo 2014 del Código Civil regula esta figura y lo preceptuado por dicho concepto. Podemos definir al tercero registral como aquel que adquirió un derecho a título oneroso, con buena fe, de quien aparece en el Registro con derecho inscrito y que ha procedido a inscribir su adquisición. Habría que agregar, como lo señala la exposición de motivos, que será tercero registral respecto de cualquier acto o contrato en cuya celebración no ha intervenido y que a su vez no se haya inscrito o se inscriba con posterioridad (Balarezo 1997: A-108). 


\section{ANÁLISIS DEL CASO}

\subsection{Finalidad de las medidas cautelares}

Para hacer un análisis adecuado de la sentencia del TC debemos empezar señalando qué finalidad tienen las medidas cautelares en sentido general, y de forma especial, la finalidad de la anotación de demanda.

Las medidas cautelares tienen como objeto asegurar la eficacia de la decisión final, sirven para asegurar el resultado de esta, así como para brindar, por último, la tutela judicial que se buscaba al postular la pretensión procesal con la demanda.

Podemos decir que las medidas cautelares, sea la que fuere su naturaleza o finalidad, ayudan ineluctablemente a fortalecer el valor «eficacia» del proceso civil. Eficacia que resulta inescindible con la tutela jurisdiccional, pues básicamente son ambas las que de modo implícito busca el justiciable cuando usa el proceso como instrumento para el logro de su pretensión, que según Peyrano puede satisfacer formalmente la sed de justicia o calmarla sustancialmente ${ }^{4}$.

A su momento, el profesor Juan Monroy Gálvez, al referirse al valor eficacia relacionado con la medida cautelar, advierte que resulta imprescindible que el proceso cuente con un instituto que permita asegurar que la duración del proceso no convierta en ilusorio el

4 Sobre la eficacia que pudieran generar las sentencias que crean jurisprudencia, desde el punto de vista de su contenido, Peyrano señala: así es, por ejemplo, que abundan los fallos de la Corte Suprema de Justicia de la Nación que insisten en la necesidad de dictar decisiones jurisdiccionales «eficaces», ven la repulsa de aquellas sentencias cuyo único mérito sea el de constituir un grupo de frases bellamente escritas pero carentes del afán de hacer justicia en serio. Más vale a veces un empeño desmañado en procura de alcanzar el valor «justicia», que una estructura impecable y elegante pero despreocupada por el contenido de la resolución dictada. Continúa diciendo que la pepita de oro de la justicia se halla oculta en el cieno de una sentencia primorosa (1981: 7). 
cumplimiento del fallo definitivo. Este instituto no es otro que la medida cautelar. Como se advierte, este se encuentra íntimamente ligado al valor eficacia en el proceso civil. Apreciamos en concreto la finalidad de dicho instituto (1987: 16).

Hemos señalado que las medidas cautelares han basado su desarrollo en la existencia del "proceso» aliado a los valores de «justicia»y «eficacia». Por tanto, siempre encontramos una conexión entre el llamado proceso principal y el proceso cautelar, y entre estos existe un elemento que los convierte en inescindibles: EL TIEMPO.

La duración que tenga el proceso principal, es decir, el tiempo que demore el juez en declarar la certeza de la pretensión contenida en la demanda y el perjuicio que pueda ocasionar tal dilación en contra del pretensor, ha sido motivo también de pronunciamiento por la doctrina, y ha sido considerada como otro elemento en el que se funda la teoría de las medidas cautelares.

Esta relación ya anotada y el tiempo que media entre ambos procesos, fueron apreciados por Montero, quien precisa que ni el juzgar puede realizarse de forma inmediata, ni el hacer ejecutar lo juzgado es instantáneo. Una y otra actividad exigen tiempo, tiempo para poder decidir con justicia, tiempo para sustituir esa conducta al condenado que voluntariamente no quiera realizar (1989: 15). En su oportunidad, Calamandrei - en Introduzione allo studio sistematico dei provvedimenti cautelari- sobre el mismo punto nos enseña que el tiempo, en definitiva, es consustancial al proceso y necesario para hacer bien. Definitivamente el tiempo que discurre entre la interposición de la demanda que genera el proceso principal y la emisión de sentencia es siempre en contra de quien solicita tutela.

Tratándose de medidas cautelares, el antiguo principio litis pendente nihil innovetur, por el cual la situación jurídica debatida debe mantenerse hasta la emisión de la sentencia, debe dejar de 
observarse cuando se aprecie a priori la posibilidad de que se frustre la pretensión del actor.

Así, el fenómeno relacionado con el tiempo, llamado duración del proceso principal, hay que mirarlo desde dos aristas totalmente opuestas y contradictorias entre sí. Por un lado, porque este espacio de tiempo ayuda a dar certeza de la petición del actor en cuanto a sus derechos sustantivos; $y$, por otro lado, porque esta dilación - justificada a veces y otras no- le brinda amplias facilidades al sujeto procesal pasivo para intentar la burla de los derechos que le corresponden al demandante. Esta segunda posibilidad dio opción para crear mecanismos orientados a evitar que la efectividad de una sentencia se vea agraviada por la demora del proceso; por ello Chiovenda reparó en considerar que la necesidad del proceso para obtener razón no debe convertirse en daño para quien teniéndola se ve obligado a acudir a los tribunales.

Guinchard, citado por María Pía Calderón, para referirse a la necesidad de las medidas cautelares y el transcurso del tiempo ocurrido entre la interposición de la demanda y la emisión de la sentencia, nos refiere que el cambio radical que se ha producido en nuestra sociedad añade una perspectiva nueva en la problemática de las medidas cautelares. La estabilidad de las sociedades antiguas se acomodaba relativamente bien a la duración del proceso soportando de forma paciente la espera. Nuestra sociedad contemporánea, agitada e inquieta, necesita sin embargo respuesta inmediata para la solución de sus conflictos (1992: 15). Por ello mientras el legislador no cree mecanismos adecuados para esta acelerada sociedad, el recurso a las medidas cautelares se convertirá en instrumento para combatir la duración del proceso.

Ramos Méndez, citado por Gozaíni, al referirse al tema en cuestión nos habla de que el fundamento que autoriza las medidas cautelares se encuentra en la incidencia del tiempo en el proceso, 
el cual, naturalmente, ocupa un largo plazo hasta que llega al reconocimiento del derecho. La lentitud de la justicia se cubre preventivamente con estas medidas provisionales, obrando como paliativos de los riesgos a los que puede llevar la tardanza en obtener un pronunciamiento judicial (1992: 787).

En conclusión, debemos memorar que las medidas cautelares en el proceso civil cumplen dos funciones muy marcadas: la primera porque se columbran como medios de satisfacción de intereses que esperan una respuesta del órgano jurisdiccional; y la segunda porque operan como un reaseguro (Gozaíni 1992: 788) de la sentencia, ya que también está de por medio el interés del mismo órgano jurisdiccional para hacer eficaces sus decisiones.

No cabe duda de que la tutela cautelar juega un papel preponderante en el proceso judicial, su misión principal es garantizar el resultado definitivo del proceso, es decir, sirve para hacer eficaz la decisión obtenida y, en su caso, es el mejor instrumento que hace viable la ejecución de lo decidido.

Por ello, se dice que la tutela cautelar se convierte en el mejor instrumento del proceso para lograr la eficacia de lo que se decida en su interior.

\subsection{Finalidad de la anotación de demanda}

La anotación de demanda tiene la finalidad de toda medida cautelar: garantizar el resultado de la decisión final, darle eficacia. Pero, como medida cautelar especial, tiene una finalidad concreta: dar publicidad a un proceso judicial a través del Registro.

En ese sentido, la finalidad concreta de la anotación de demanda es hacer saber a todos a través del Registro que existe en el Poder Judicial un proceso judicial iniciado que podría de alguna manera modificar la realidad registral. 
La anotación de demanda busca un propósito específico, que todos aquellos que se vinculen con determinado bien a través del Registro sepan de la existencia de un proceso judicial en el cual se encuentra discutiendo un bien o un derecho registrado en la partida en la que se inscribió el mandato judicial y que podría producirse un cambio de relevancia de la información registral.

La idea de esta publicidad que genera la anotación de demanda es quebrar cualquier posibilidad de alegación de buena fe de todo aquel que se vincule con el bien o derecho a través del Registro. Además, si se vincula con el bien o derecho en el Registro después de anotada la demanda, quedará sujeto al resultado final del proceso, lo afectará la cosa juzgada aunque no haya sido parte del proceso.

La profesora Ledesma señala que el objeto de la anotación busca asegurar la publicidad de los procesos relativos a bienes inmuebles o muebles registrables frente a la eventualidad de que las sentencias que en ellos recaigan hayan de ser opuestas a terceros adquirientes del bien litigioso o a cuyo favor se constituya un derecho real sobre este (2016: 100).

\section{3. ¿La anotación de demanda sirve para garantizar acreencias dinerarias?}

Si la finalidad de la medida cautelar de anotación de demanda es hacer pública la existencia de un proceso judicial cuyo resultado va a modificar el Registro, entonces podríamos sostener que esta medida cautelar podría servir para garantizar procesos que en concreto tienen postuladas pretensiones que busquen de forma directa o indirecta modificar el Registro con la cosa juzgada.

Esto significa que el juez, para dictar una medida cautelar de esta naturaleza, debería tener presente que solo será admisible si busca dar eficacia a lo que se decida con la sentencia firme. 
En los procesos en los que se discute el pago de una suma dineraria, se pone en evidencia la existencia de un derecho de crédito, el demandante es titular de este derecho. Ello le permite hacer viable la exigencia del derecho de crédito en el proceso, a través de la demanda, exigiendo que el demandado cumpla con pagarle determinada suma de dinero. Esta acreencia puede ser de orden civil o de naturaleza laboral.

Los procesos de obligación de dar suma de dinero no tienen como referencia el Registro, ya que las acreencias o los derechos de crédito normalmente no tienen vinculación con aquel. En ese sentido, si lo que se busca es garantizar el resultado de la decisión final, la medida cautelar adecuada en estos casos son los embargos, y de ser posible, un secuestro conservativo.

La anotación de demanda no es la medida cautelar que sirve para garantizar el resultado de la decisión final, pues la sentencia terminará ordenando el pago de una suma de dinero. $Y$ si ese es el resultado final del proceso, las medidas cautelares para futura ejecución forzada serían las adecuadas para lograr garantizar las sumas que debe pagar el demandado.

En ese orden de cosas, tenemos que señalar que la anotación de demanda no es la medida cautelar adecuada para garantizar el resultado final del proceso en el que se pretende cobrar una acreencia dineraria ${ }^{5}$. Por el contrario, tiene por objeto poner en conocimiento público la existencia del pleito a fin de que la enajenación o negociación que pudiera recaer sobre tales bienes

5 A través de la anotación de demanda se persigue asegurar la publicidad del proceso a fin de oponer a los terceros la sentencia que respecto de él se dicte, de modo que no puedan invocar buena fe. A través de la publicidad de la litis el tercer adquiriente del inmueble, o aquel en cuyo favor se constituye un derecho real, no pueden alegar ignorancia, debiendo soportar, en consecuencia, los efectos de la sentencia; de ahí que dicha cautela no impida o afecte la disposición del bien, el que es susceptible de embargo o enajenación (Ledesma 2016: 105). 
(individualizados o como integrantes de un patrimonio) no pueda producir la liberación referida (Rivas 2005: 192).

\subsection{La anotación de demanda en el caso particular}

Encontramos en el caso materia de estudio dos situaciones diferentes: la primera tiene que ver con la pertinencia (si es adecuada) de la anotación de demanda para garantizar el resultado del proceso en el que al parecer se discute un derecho de naturaleza laboral (acreencia laboral). La segunda se refiere a la posibilidad de levantar la anotación de demanda cuando ya se produjo la adjudicación (después del remate) o si tiene algún propósito mantenerla de acuerdo con las circunstancias.

En cuanto a la primera situación, me parece que la medida cautelar de anotación de demanda no era la adecuada para garantizar el resultado del proceso laboral, puesto que el resultado del caso no iba a lograr una modificación del Registro.

Se publicitó la litis con el objeto de que se supiera que existía un proceso laboral en el que los trabajadores de la demandada pretendían cobrar una acreencia laboral. Sin embargo, la finalidad de este proceso no se vincula por ningún lado con la modificación del Registro, sino más bien con la satisfacción dineraria que coberture los conceptos de naturaleza laboral demandados. Para este propósito simplemente se encuentran previstos los embargos. Por ello en este caso la medida cautelar idónea para coberturar acreencias de naturaleza laboral son los embargos, no funciona la anotación de demanda, no es útil.

Al parecer los trabajadores buscaban que la empresa demandada no realice ningún acto de disposición del bien y que al lograr anotar la demanda se disuadía a cualquier comprador de buena fe de adquirir la propiedad de este o a gravarlo. Un inmueble con anotación de 
demanda inscrita disuade a cualquier interesado de vincularse con el bien a través del Registro.

Consideramos que el juez del proceso laboral admitió de forma incorrecta la medida de anotación de demanda, pues se quebrantó el criterio de adecuación del que depende la dación de cualquier medida cautelar, adecuación en el sentido de que la medida cautelar solicitada y ordenada siempre debe tener correspondencia con la pretensión postulada en la demanda, que sirva para garantizar la eficacia de lo que se decida en la sentencia firme. Lo que no se produce en este caso en particular, ya que la medida cautelar que garantizaba la eficacia de lo decidido era el embargo.

Esta situación no fue analizada por el voto en mayoría, que decidió no levantar la medida cautelar, y argumentando un supuesto orden de prelación para el cobro de la acreencia señaló: «La conservación de la anotación de demanda es la única manera de determinar el orden de prelación en el que se tengan que satisfacer las acreencias laborales judicializadas», lo cual, en mi concepto, no es admisible, por dos aspectos muy puntuales:

a) En este caso, se trata de derechos laborales de la misma naturaleza y en consecuencia se encuentran en la misma situación de paridad o igualdad, ninguno de ellos es mejor que el otro y la anotación de demanda sobre un bien que ya fue vendido por remate no le genera ningún tipo de prelación respecto de otro acreedor laboral que tenga o no anotada la demanda sobre el mismo inmueble, simplemente porque este inmueble ya no es de propiedad del empleador y respecto de él no se podrá realizar ninguna exigencia de naturaleza económica para satisfacer el crédito laboral.

b) Si la prelación fuera sobre otro acreedor embargante que hubiera anotado el embargo en la misma partida registral, se debe seguir la misma regla, porque con el remate todas las 
anotaciones de embargo se levantaron y, en consecuencia, no habría con quién comparar la prelación, salvo que se quiera comparar con otras anotaciones de demanda sobre el mismo bien, situación que ya fue señalada.

Por ello, respecto de la segunda situación, consideramos que no existe razón suficiente en la resolución del Tribunal Constitucional (en mayoría) para haber denegado el levantamiento de la anotación de demanda, en primer lugar, porque no era la medida cautelar adecuada para garantizar acreencias laborales; en segundo lugar, porque no es atendible el argumento de que serviría para lograr una prioridad a través del Registro, ya que el inmueble rematado tiene otro dueño y ya no sirve para el propósito que buscaban los trabajadores titulares de la anotación de demanda; $y$, en tercer lugar, porque mantener anotadas las demandas en un inmueble que ya no se podrá afectar debido a que fue rematado y tiene otro propietario, y que el monto obtenido debe ser entregado a los acreedores que el juez disponga, afecta gravemente el derecho de propiedad de quien adquirió de buena fe el inmueble.

Si bien el adjudicatario sabía de la existencia de las anotaciones de demanda y que no se podían levantar en este caso por disposición legal, la restricción al derecho de propiedad resulta grave, si tomamos en cuenta que las citadas anotaciones no cumplen ningún fin práctico para los intereses de los acreedores laborales porque el inmueble ya fue rematado. En todo caso, su interés se debe trasladar al monto obtenido en el remate judicial, si eso es lo que buscan con el proceso laboral.

En ese sentido, considero que la negativa de levantar la medida cautelar de anotación de demanda por la Sala Superior y con el voto en mayoría del Tribunal Constitucional afecta el derecho de propiedad del actor, puesto que prácticamente lo saca del tráfico de bienes al mantener anotadas las demandas. 
Debe tomarse en cuenta que si bien es cierto que la anotación de demanda en el Registro no impide la enajenación del inmueble, el adjudicatario podría disponer de él aun con estas anotaciones. Pero, en este caso en particular, considero que ese no es el tema de discusión. La controversia se ubica en otro plano, esto es, que las anotaciones de demanda se encuentran involucradas con un proceso en el que discuten acreencias laborales. Por ende, estas anotaciones no garantizan para nada la eficacia de la decisión final que se emita en ese proceso, menos se puede decir que sirven para definir prelación en el pago de las acreencias laborales, debido a que el inmueble ya fue transferido y las acreencias laborales tienen el mismo rango.

\section{POSICIÓN DEL TC EN MAYORÍA PARA DESESTIMAR LA DEMANDA}

Como hemos señalado en líneas precedentes son tres los argumentos que sustentan la decisión en mayoría para desestimar la demanda de amparo:

a) De levantarse la medida cautelar de anotación de demanda, desaparece la posibilidad de que alguno de los acreedores pueda reclamar la prioridad en la satisfacción de sus créditos.

b) Se trata de una medida necesaria, que si bien obstaculiza el poder de disposición del bien, tiene también por finalidad satisfacer ciertas exigencias relacionadas con el principio de seguridad jurídica (satisfacción de derecho laboral).

c) Es una carga no excesiva que será llevada temporalmente por las personas que adquieren un bien mediante remate judicial.

Veamos cada uno de ellos. El argumento «a» ya lo hemos referido, y me parece que no es el adecuado para sustentar la decisión, puesto que el bien inmueble ya se remató a un tercero y la discusión respecto del pago a cada uno de los trabajadores que tienen procesos laborales 
contra la citada cooperativa ya no se relaciona con el bien inmueble rematado, sino con la suma de dinero que se obtuvo en el remate.

Por lo que si hubiera tercerías de derecho preferente o algún trámite de acreedor no ejecutante derivado del proceso en el que remató el bien, las acreencias, en mi opinión, se encuentran en el mismo rango (son créditos laborales). Por ello la suma obtenida debería ser pagada a todos aquellos que la reclaman a prorrata, hasta donde alcance la suma obtenida en el remate. Los presupuestos para la procedencia del pedido del acreedor no ejecutante son, por un lado, que el peticionante tenga proceso con sentencia firme que le reconozca una acreencia impaga y que tenga afectado el mismo bien. Luego será el juez quien regule en su decisión el pago de su crédito según su naturaleza. Si los trabajadores pidieron que se les pague su crédito con la suma obtenida en el remate, esta se debe prorratear entre todos los que la pidan, siempre que cumplan con estas exigencias.

La razón «b» es más débil aun, porque se plantea como argumento que la anotación de demanda de alguna manera garantiza que el trabajador pueda ver satisfecho su crédito laboral, lo cual no es cierto si volvemos a revisar la finalidad de la medida cautelar de anotación de demanda. Esta medida únicamente publicitaba la litis y evitaba que terceros se vinculen con el inmueble y luego puedan alegar buena fe. Pero no es una medida cautelar que pueda brindar satisfacción futura de naturaleza económica a quien la obtuvo.

En relación con el argumento «c», la anotación de demanda es una medida cautelar y como tal tiene efectos provisorios que se vinculan con la finalidad del proceso en el que se obtuvo. Si el proceso laboral terminó y la anotación de demanda no le servirá al trabajador para ejecutar el inmueble porque no es un embargo, sino que solo le servía (y mal) para publicitar la litis, entonces, esa provisoriedad ya concluyó y debía levantarse porque no le representa 
ninguna utilidad al demandante en el proceso laboral. Además perjudica enormemente las expectativas del adjudicatario de gozar plenamente el derecho de propiedad que tiene sobre el bien, pues limitan su derecho de disposición, negociación y gravamen.

En suma, considero que las razones mostradas para desestimar la demanda de amparo, en este caso, no son las más adecuadas, y al parecer nos encontramos en un supuesto de motivación aparente, al tener una decisión que no soporta su validez en el plano de la justificación externa.

\section{CONCLUSIONES}

1. La anotación de demanda es una medida cautelar que no tiene por finalidad garantizar decisiones que se vinculen con créditos laborales. Busca publicitar una litis que podría generar con la sentencia firme un cambio en el Registro.

2. En los procesos laborales donde se discuten acreencias laborales las medidas cautelares idóneas son las medidas para futura ejecución forzada: los embargos o el secuestro conservativo. La anotación de demanda no es la medida cautelar adecuada.

3. Si el inmueble se remató y la medida cautelar de anotación de demanda proviene de un proceso laboral en el que se discute una acreencia laboral, esta perdió utilidad y, por tanto, debe levantarse, pues afecta de forma grave el derecho de propiedad del adjudicatario.

4. Las medidas cautelares de anotación de demanda que provienen de procesos que buscan satisfacer créditos laborales no sirven para definir la prelación en el pago de crédito, ya que estos créditos tienen el mismo rango y se encuentran en plano de paridad. Además, la prelación para fines de cobro del crédito no se establece con una anotación de demanda, sino con un embargo. 
5. Mantener las anotaciones de demanda que no tienen ninguna utilidad para aquellos que lograron la cosa juzgada —en el caso en particular - afecta el derecho de propiedad del adjudicatario.

\section{REFERENCIAS BIBLIOGRÁFICAS}

Alsina, Hugo (1941-1943). Tratado teórico y práctico de derecho procesal civil y comercial. 3 tomos. Buenos Aires: Cía. Argentina de Editores.

Balarezo Forttini, Juan Ramón (1997). Las anotaciones preventivas en normas legales. Tomo n. ${ }^{\circ}$ 257, A-107.

Calderón Cuadrado, María Pía (1992). Las medidas cautelares indeterminadas en el proceso civil. Barcelona: Civitas.

De Lazzari, Eduardo Néstor (1998). Medidas cautelares. Tomo I. La Plata: Editorial Platense.

Gozaíni, Osvaldo Alfredo (1992). Derecho procesal civil. Tomo I: Teoría general del proceso. Vol. II. Buenos Aires: Ediar.

Ledesma NARvÁEz, Marianella (2016). Las medidas cautelares en el proceso civil. Lima: Gaceta Jurídica.

Monroy Gálvez, Juan (1987). Temas de proceso civil. Lima: Studium.

Monroy Palacios, Juan (2002). Bases para la formación de una teoría cautelar. Lima: Comunidad.

Montero Aroca, Juan et al. (1989). Derecho jurisdiccional II-2. Barcelona: Librería Bosch.

Peyrano, Jorge (1981). Medida cautelar innovativa. Buenos Aires: Ediciones Depalma. 
Podetti, J. Ramiro (1943). «Las medidas cautelares y el embargo preventivo de los frutos de las cosas litigiosas». Revista de Derecho Procesal Civil, I, 138-153.

PrIORI PosAdA, Giovanni(2006). La tutela cautelar: su configuración como derecho fundamental. Lima: ARA.

Rivas, Adolfo (2005). Las medidas cautelares en el derecho peruano. Lima: Jurista Editores. 